This is an electronic reprint of the original article. This reprint may differ from the original in pagination and typographic detail.

Author(s): Peuronen, Anssi; Hänninen, Mikko M.; Tuononen, Heikki

Title: $\quad$ Pyrazolium- and 1,2-Cyclopentadiene-Based Ligands as $\sigma$-Donors: a Theoretical Study of Electronic Structure and Bonding

Year: $\quad 2012$

Version:

Please cite the original version:

Peuronen, A., Hänninen, M. M., \& Tuononen, H. (2012). Pyrazolium- and 1,2Cyclopentadiene-Based Ligands as $\sigma$-Donors: a Theoretical Study of Electronic Structure and Bonding. Inorganic Chemistry, 51(4), 2577-2587.

https://doi.org/10.1021/ic202546a

All material supplied via JYX is protected by copyright and other intellectual property rights, and duplication or sale of all or part of any of the repository collections is not permitted, except that material may be duplicated by you for your research use or educational purposes in electronic or print form. You must obtain permission for any other use. Electronic or print copies may not be offered, whether for sale or otherwise to anyone who is not an authorised user. 


\title{
Pyrazolium- and 1,2-Cyclopentadiene-based Ligands as $\sigma$-Donors: a Theoretical Study of Electronic Structure and Bonding
}

Anssi Peuronen, Mikko M. Hänninen and Heikki M. Tuononen*[a]

[a] Department of Chemistry, PO Box 35, Fl-40014 University of Jyväskylä, Finland

* Corresponding author: Phone: +358-14-260-2500; Fax: +358-14-260-2501; E-mail: heikki.m.tuononen@jyu.fi

\begin{abstract}
A high-level theoretical investigation of 1,2-cyclopentadiene (4) was performed using density functional theory and wave function methods. The results reveal that, in contrast to earlier assumptions, the ground state of this ephemeral "allene" is carbenelike with a small diradical component. Furthermore, the electronic structure and chemistry of $\mathbf{4}$ are found to parallel that of 1,2,4,6-cycloheptatetraene: both molecules possess a low-lying excited singlet state with a closed-shell carbenic structure, enabling rich coordination chemistry. Energy decomposition analyses conducted for currently unknown metal complexes of $\mathbf{4}$ as well as those involving stable carbenes based on the pyrazolium framework (a.k.a. "bent allenes" or remote N-heterocyclic carbenes) indicate that all investigated ligands form particularly strong metal-carbon bonds. Most notably, without exocyclic $\pi$-type substituents, 4 and pyrazolin-4-ylidenes are the strongest donor ligands examined, in large part due to the energy and shape of their highest occupied molecular orbital. As a whole, the current work opens a new chapter in the chemistry of 1,2-cyclopentadiene, which is hoped to spark renewed interest among experimentalists. In addition, results from the conducted bonding analyses underline that more emphasis should be placed on purely carbocyclic carbenes as unprecedented $\sigma$-donor strengths can be realized through this route.
\end{abstract}




\section{Introduction}

The recent reports by Bertrand and co-workers on small heteroatomic and all-carbon cyclic allenes $1\left(\mathrm{Ar}=2,6-\mathrm{Me}_{2} \mathrm{C}_{6} \mathrm{H}_{3}\right)$ and $\mathbf{2}\left(\mathrm{R}_{2} \mathrm{~N}=\right.$ piperidino $)$, respectively, have initiated great interest towards the electronic structures and reactivities of these compounds. ${ }^{1}$ Cyclic all-carbon allenes with ring sizes less than eight are in general too unstable to be isolated due to the increased ring strain which not only destabilizes the molecules thermodynamically but also destroys the degeneracy of the $\pi$-manifold, thereby lowering the frontier orbital energy gap. ${ }^{2}$ Consequently, the allenes $\mathbf{1}$ and $\mathbf{2}$ with fiveand four-membered rings obtain additional stabilization through exocyclic donor groups which disrupt the $\pi$-system and counterbalance the effects of ring strain. ${ }^{1}$ As evidenced by detailed theoretical investigations, ${ }^{3}$ the push-push substitution pattern in $\mathbf{1}$ is paramount for its stability and readily supersedes contributions from either cyclic electron delocalization or steric bulk. Although similar electronic effects play an important role for the improved stability of $\mathbf{2}$ as well, the allene is only persistent and cannot be isolated as a free species even at low temperatures. ${ }^{1 \mathrm{~b}}$

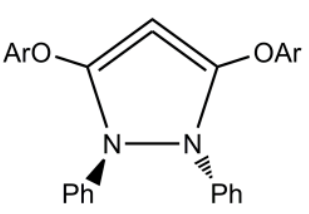

1

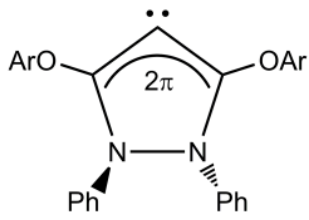

$1^{\prime}$

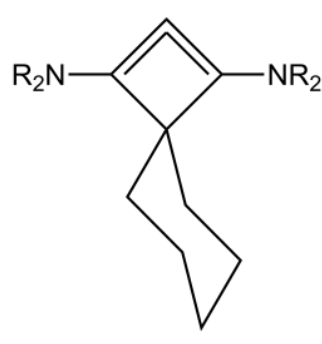

2

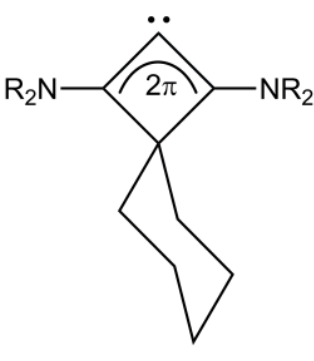

2'

The enhanced stability of $\mathbf{1}$ and $\mathbf{2}$ has permitted the exploration of their chemistry which differs from that traditionally associated with allenes. ${ }^{1,4}$ Due to the extreme bending of the molecular skeleton, both compounds adopt an electronic structure in which the central carbon atom is carbene-like and bears a $\sigma$-lone pair. ${ }^{3}$ Strictly speaking, neither $\mathbf{1}$ nor $\mathbf{2}$ formally classifies as an allene and a more appropriate description of their bonding situation is given by the extended Lewis structures $\mathbf{1}^{\prime}$ and 2'. This readily explains why the new "allenes" are able to function as facile two-electron donors and 
bind to metals strictly in $\eta^{1}$ fashion $c f . \eta^{2}$ coordination via $\mathrm{C}=\mathrm{C}$ double bond in classical

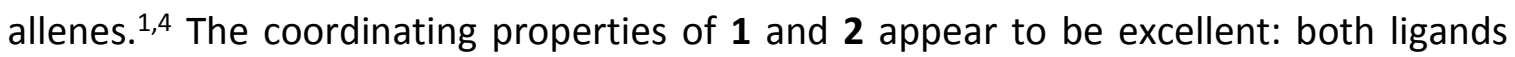
display tighter binding to metal centers than either phosphines or $\mathrm{N}$-heterocyclic carbenes (NHCs) as evidenced by infrared analyses of the corresponding rhodium(I) dicarbonyl chloride complexes. ${ }^{1}$ Furthermore, the push-push substitution pattern provides $\mathbf{1}$ and $\mathbf{2}$ an additional level of electronic flexibility because their $\pi$-systems are polarized towards the central carbon atom. ${ }^{1 b, 3 b, 5}$ This is reminiscent of the zero-valent carbon(0) nature in carbodiphosphoranes and related systems, as discussed recently by Frenking and Bertrand. ${ }^{6}$ A direct manifestation of the non-uniform $\pi$-density in $\mathbf{1}$ and $\mathbf{2}$ is that they can both undergo double protonation at the central carbon atom $c f$. protonation at the terminal carbon atom in classical allenes. ${ }^{1 b, 3 b}$

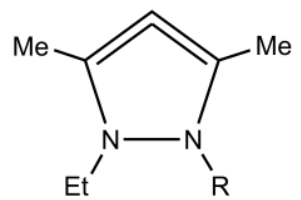

3

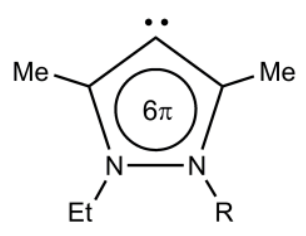

$3^{\prime}$

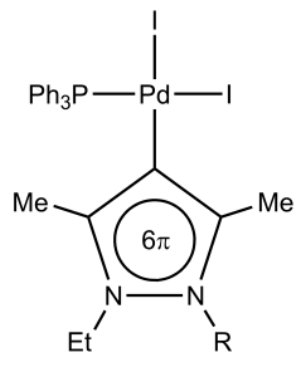

3-Pd

While a single exocyclic substituent at each terminus of the CCC moiety is sufficient to make 1 thermally stable and isolable, this ligand has proven useful even in the absence of $\pi$-donating groups. In fact, already in 2007 Han and Huynh prepared metal complexes of unsubstituted pyrazolin-4-ylidenes, $3(R=M e, P h)$, via oxidative addition of an iodinated pyrazolium precursor to a low-valent palladium metal. ${ }^{7}$ Similarly to $\mathbf{1}$, the ligands $\mathbf{3}$ can formally be considered derivatives of a cyclic allene but, according to theoretical calculations, their electronic structures are characterized by the presence of a $\sigma$-type lone pair at the central carbon atom as well as $\pi$-delocalization, $\mathbf{3}^{\prime}$, $c f$. formally isoelectronic NHCs based on imidazol-2-ylidene. ${ }^{3}$ Thus, compounds $\mathbf{3}$ were originally described as remote $\mathrm{N}$-heterocyclic carbenes ( $r \mathrm{NHCs}$ ) which is in accord with the similarities in the chemical behavior of the two types of compounds while at the same time underlining the distant location of the two heteroatoms with respect to the 
carbenic carbon atom. ${ }^{7}$ In contrast to the instability of the pure ligands, the derived palladium systems, such as $\mathbf{3}-\mathbf{P d}$, are thermally stable and isolable and can be utilized as highly efficient catalysts in $\mathrm{C}-\mathrm{C}$ and $\mathrm{C}-\mathrm{N}$ coupling reactions. ${ }^{8}$ Clearly, the in situ coordination of $\mathbf{3}$ to a metal center dominates over other electronic effects and provides an efficient mechanism for stabilization of $\mathbf{3}$ as chemically useful complexes.

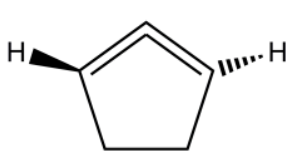

4

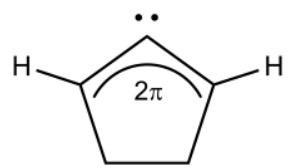

$4^{\prime}$

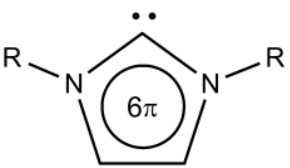

5

The structural relationship of compounds 1 and 3 raises an important question of how further modifications to the molecular framework would affect the properties of the compounds thus formed. Of particular interest is whether the replacement of endocyclic nitrogen atoms by carbon would give rise to stable systems formally based on 1,2-cyclopentadiene, $\mathbf{4}, c f$. the relationship of $\mathbf{2}$ to the diradical 1,2 -cyclobutadiene. ${ }^{1 \mathrm{~b}}$ Up to now, very little is known about this ephemeral allene. Experimentally, Balci et al. have reported indirect evidence for the generation of derivatives of $\mathbf{4}$ in a form of two trapping products. ${ }^{9}$ Theoretically, the electronic structure of the parent compound has been discussed in two contributions by Johnson and co-workers. ${ }^{10}$ In their earlier paper from 1985, the authors address that 4 may have a chiral allenic ground state with a low barrier for racemization. However, a computational re-analysis using density functional theory predicted a fully planar singlet diradical form to be the global minimum. In a recent communication, ${ }^{3 a}$ we noted in passing that the ground state of $\mathbf{4}$ appears to be chiral, multiconfigurational and dominated by the presence of a $\sigma$-lone pair, 4'. Taking one step further, this result implies that it might be possible to capture derivatives of 1,2-cyclopentadiene using in situ metallation akin to 2. Furthermore, if the ground state of 4 contains only a minor diradical component, it can be envisaged that its metal complexes might be stable even without exocyclic $\pi$-donating substituents akin to $3-\mathbf{P d}$. 
In the current contribution, we present results from quantum chemical analyses of bonding in coordination complexes of 1, 3 and $\mathbf{4}$ in relation to similar systems employing imidazol-2-ylidenes, 5 ( $\mathrm{R}=$ alkyl, aryl), as ligands. The scope of this paper is twofold. Firstly, we set out to determine the relationship of $\mathbf{4}$ to $\mathbf{1}$ and $\mathbf{3}$ and whether it could be used as a novel two-electron donor. To this end, a thorough theoretical investigation of the electronic structure of 1,2-cyclopentadiene needed to be performed to fully resolve the ambiguities in the published data. Secondly, our mission was to probe the binding properties of 1, 3 and $\mathbf{4}$ which largely determines their behavior as ligands. At present, experimental and computational data on the compounds are scarce: infrared carbonyl stretching frequencies are only available for metal complexes of $\mathbf{1}$ and the reported bonding analyses have focused solely on the zero-valent nature of the carbenic carbon center. ${ }^{1 \mathrm{a}, 5}$ Consequently, our work is the first detailed investigation of metal-carbon bonding in coordination complexes of $\mathbf{1}$ and $\mathbf{3}$. The results show that 1,2cyclopentadiene and its derivatives behave as strong $\sigma$-donors and form stable $\eta^{1}$ complexes with a range of different transition metals. Furthermore, the trends in calculated metal-ligand interaction energies correlate well with the electronic structures of the investigated ligands, offering a rationale for the design of new twoelectron donors with improved binding properties. 


\section{Computational Details}

All calculations were done with the Gaussian 09, ${ }^{11}$ Molpro $2009.1^{12}$ and ADF $2009.01^{13}$ programs. The geometry of 1,2-cyclopentadiene was optimized in different electronic states using the PBE1PBE density functional ${ }^{14}$ as well as wave function methods based on the complete active space (CAS) formalism ${ }^{15}$ without and with the $2^{\text {nd }}$ order perturbation theory correction (CASPT2). ${ }^{16}$ In contrast, the geometries of the studied transition metal complexes were optimized only in their ground states using density functional theory (DFT). The nature of stationary points found was assessed by calculating full Hessian matrices at all levels of theory employed. The Ahlrichs' def2TZVPP basis sets ${ }^{17}$ were used in all geometry optimizations and frequency calculations along with the respective quasi-relativistic effective core potentials for row 5 and 6 metals. ${ }^{18}$ In CAS calculations, the active space included the four highest electrons and orbitals i.e. CAS $(4,4)$. This comprises the three $\pi$-type orbitals within the CCC moiety (one occupied, two unoccupied) as well as the $\sigma$-lone pair orbital localized on the middle carbon atom, giving a balanced orbital set which is well capable of describing both planar and chiral geometries of the molecular skeleton. The choice of a CAS $(4,4)$ wave function is further supported by natural orbital occupation numbers obtained from test runs employing a progressively increased active space size.

The electronic structure of 1,2-cyclopentadiene in different electronic states was investigated in detail by performing electron localization function (ELF) ${ }^{19}$ analyses on the

CAS $(4,4)$ wave functions using the program package TopMod09. ${ }^{20}$ Metal-carbon bonding in the studied metal complexes was assessed with the energy decomposition analysis $(E D A)^{21}$ procedure as implemented in ADF2009.1.22 The analyses were performed at the PBE1PBE/def2-TZVPP optimized geometries using the PBEPBE density functional ${ }^{14 a-c}$ in together with the all electron TZP basis sets ${ }^{23}$ and the zeroth order regular approximation (ZORA) for the treatment of scalar relativistic effects. ${ }^{24}$ Neutral fragments were employed in the analyses as it represents not only the chemically most logical choice but also the best possible fragmentation scheme based on the calculated 
Hirshfield charges (minimal transfer of electrons between chosen fragments). The programs gOpenMol ${ }^{25}$ and Mercury ${ }^{26}$ were used for all visualizations. 


\section{Results and Discussion}

Electronic structure of 1,2-cyclopentadiene: The geometry of the parent compound 4 was first optimized using restricted DFT in the singlet manifold (Figure 1). The global minimum at the PBE1PBE/def2-TZVPP level corresponds to the chiral and $C_{2}$ symmetric ${ }^{1} \mathrm{~A}$ state whose main features are reminiscent of an allene-type electronic structure. However, the final Kohn-Sham orbitals display a complete transformation of one of the $\pi$-type frontier orbitals to a $\sigma$-lone pair along with a relatively small HOMO-LUMO gap of $3.2 \mathrm{eV}$. Hence, the electronic structure is clearly not that of a classical allene but more carbene-like. Furthermore, a subsequent stability analysis showed that the restricted DFT solution has an internal instability, indicative of the presence of a diradical contribution. Hence, the geometry of the molecule was re-optimized by employing a broken symmetry approach. When using different orbitals for $\alpha$ - and $\beta$-spin electrons (UPBE1PBE/def2-TZVPP), the global minimum of 4 corresponds to a planar and $C_{2 v}$ symmetric purely diradical $\left(\mathrm{S}^{2}=1.06\right){ }^{1} \mathrm{~A}_{2}$ state which resides $28 \mathrm{~kJ} \mathrm{~mol}^{-1}$ lower in energy than the chiral structure (Figures 1 and 2). Interestingly, there is also another planar $C_{2 v}$ symmetric stationary point at the DFT potential energy surface (PES): the closed-shell fully carbenic ${ }^{1} A_{1}$ state, which is located $42 \mathrm{~kJ} \mathrm{~mol}^{-1}$ higher than the diradical ${ }^{1} \mathrm{~A}_{2}$ state. This structure is, however, a first order transition state with respect to the racemization of the chiral ${ }^{1} \mathrm{~A}$ geometry.

Although the DFT investigations by Johnson et al. agree with the above findings, ${ }^{10 b}$ our preliminary wave function-based data published in an earlier communication predicted the chiral ${ }^{1} \mathrm{~A}$ state to be the ground state by a small but nevertheless a noticeable margin. ${ }^{3 a}$ Since this is essentially the result that Johnson et al. obtained in their earlier analyses, ${ }^{10 a}$ albeit using vastly smaller basis sets and energy extrapolation schemes, it is clear that a definite answer for the ground state of $\mathbf{4}$ cannot be obtained unless highly correlated levels of theory are employed. Hence, the singlet PES of 4 was re-examined using high-level multiconfigurational methods. 


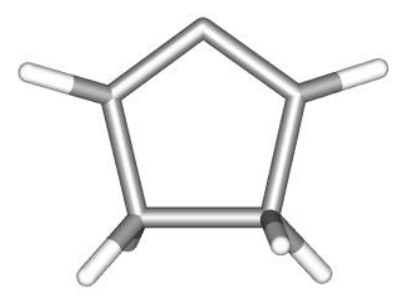

${ }^{1} \mathrm{~A}$

$$
\begin{aligned}
r(\mathrm{C}=\mathrm{C})= & 1.359 \\
& {[1.364] } \\
& (1.367)
\end{aligned}
$$

$\angle(C=C=C)=108.2$

[113.2]

(112.9)

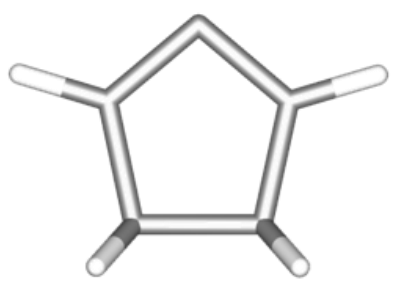

${ }^{1} \mathrm{~A}_{1}$

$$
r(\mathrm{C}=\mathrm{C})=\begin{gathered}
1.398 \\
{[1.404]} \\
(1.411) \\
\angle(\mathrm{C}=\mathrm{C}=\mathrm{C})= \\
100.0 \\
{[100.4]} \\
(99.6)
\end{gathered}
$$

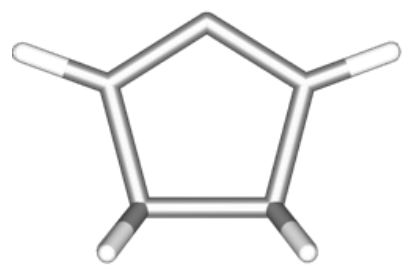

${ }^{1} \mathrm{~A}_{2}$

$$
r(\mathrm{C}=\mathrm{C})=1.368
$$

[1.379]

(1.377)

$\angle(C=C=C)=116.0$

[114.4]

(115.6)

Figure 1. Optimized geometry of $\mathbf{4}$ in the singlet manifold at the PBE1PBE/def2-TZVPP, [CAS(4,4)/def2-TZVPP] and (CASPT2/def2-TZVPP) levels of theory. Bond lengths are reported in Ångströms $(\AA \AA)$ and bond angles in degrees $\left({ }^{\circ}\right)$.

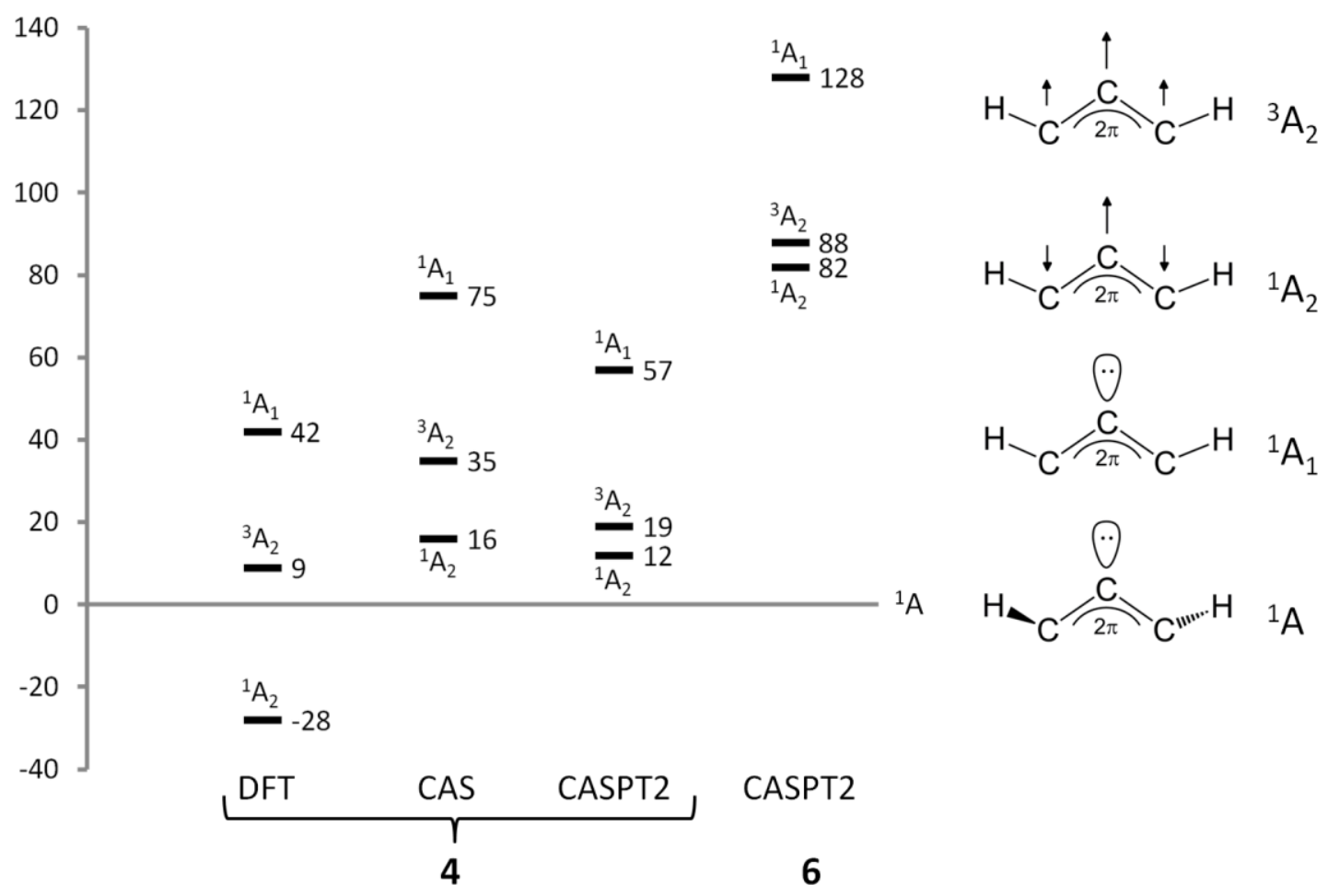

Figure 2. Relative energies (in $\mathrm{kJ} \mathrm{mol}^{-1}$ and with respect to the ${ }^{1} \mathrm{~A}$ state) of the lowest electronic states of $\mathbf{4}$ and $\mathbf{6}$ calculated at different levels of theory. Data for compound $\mathbf{6}$ taken from Reference 28. 
The structure of 4 was optimized using a CAS $(4,4) /$ def2-TZVPP wave function. The results indicate that the singlet ground state of 4 is indeed the chiral and $C_{2}$ symmetric ${ }^{1} \mathrm{~A}$ state. Its optimized CAS wave function is an admixture of two Slater determinants: a carbenic reference determinant $(\mathrm{Cl}$ vector coefficient 0.89 in the natural orbital basis) equivalent to the ${ }^{1} \mathrm{~A}_{1}$ state along with a minor contribution $(\mathrm{Cl}$ vector coefficient -0.35$)$ from its doubly HOMO $\rightarrow$ LUMO excited configuration. Consequently, the ground state of 4 is carbene-like and has a small but non-negligible diradical component.

The CAS $(4,4) /$ def2-TZVPP optimization also located the $C_{2 v}$-symmetric purely diradical ${ }^{1} \mathrm{~A}_{2}$ state $\left(\Delta E=16 \mathrm{~kJ} \mathrm{~mol}^{-1}\right)$ and the closed-shell fully carbenic ${ }^{1} \mathrm{~A}_{1}$ state $(\Delta E=75$ $\mathrm{kJ} \mathrm{mol}^{-1}$ ) from the PES of 4 (Figure 2). For both states, a subsequent frequency analysis revealed one imaginary normal mode that corresponds to an $a_{2}$-symmetric out-of-plane vibration leading to the $C_{2}$ symmetric ground state (racemization). This is in contrast to the DFT results which identified the diradical state as a true minimum with all frequencies real. However, unrestricted DFT is known to fail by construction in describing pure singlet diradicals for which a Kohn-Sham determinant does not represent a true electronic state. ${ }^{27}$ In the current case, this leads to artificial stabilization of the ${ }^{1} A_{2}$ state at the DFT level, giving a false global minimum and a failure in finding a diradical component within the chiral molecular framework. This conclusion is further supported by subsequent calculations at the CASPT2 level.

Though not a topic of this paper, we also investigated the electronic structure of 4 within the triplet manifold. As expected based on the calculated data for the singlet states, the lowest triplet state of $\mathbf{4}$ has $A_{2}$ symmetry and it resides $35 \mathrm{~kJ} \mathrm{~mol}^{-1}$ higher in energy than the ground state at the CAS $(4,4) /$ def2-TZVPP level.

Although the CAS ansatz takes care of the static part of the correlation energy, it is nevertheless a zeroth order approximation with respect to dynamic electron correlation effects. Hence, to further increase the validity of the theoretical predictions, a second order perturbation theory (PT2) correction was applied to the CAS $(4,4)$ wave function. The results show that the inclusion of dynamic electron correlation has virtually no effect on the predicted metrical parameters of 4 (Figure 1) and it introduces only a 
minor correction to the relative energies of the different electronic states (Figure 2). The chiral $C_{2}$-symmetric ${ }^{1} \mathrm{~A}$ state remains the global minimum also at the fully correlated CASPT2 level with an energy separation of 12 and $57 \mathrm{~kJ} \mathrm{~mol}^{-1}$ to the $C_{2 v}$-symmetric ${ }^{1} \mathrm{~A}_{2}$ and ${ }^{1} A_{1}$ states, respectively, which are both first order saddle points on the PES. We also note that, even at the CASPT2 level, the triplet $A_{2}$ symmetric state resides $7 \mathrm{~kJ} \mathrm{~mol}^{-1}$ higher in energy than the corresponding singlet, which constitutes a formal violation of the molecular analogue of the Hund's rule. This can be understood by considering the disjointed nature of the singly occupied frontier orbitals, which ensures that the triplet state wave function is not energetically preferred over the singlet as the two electrons occupying the orbitals will never appear in the same region of space be their spins parallel or anti-parallel. Thus, in such a case, the multiplicity of the ground state is determined by Coulombic electron-electron interactions between the two electrons in the partially filled MOs and the electrons in the other lower-lying orbitals.

To summarize, we conclude that the global minimum of 1,2-cyclopentadiene is the $\mathrm{C}_{2}$-symmetric chiral ${ }^{1} \mathrm{~A}$ state whose wave function is an uneven combination of the carbenic reference determinant and its HOMO $\rightarrow$ LUMO doubly excited configuration. Hence, the electronic structure of $\mathbf{4}$ is clearly not that of an allene and the molecule should therefore not be described as one. The presence of diradical character in the ground state of 1,2-cyclopentadiene is fully in line with its experimentally observed reactivity ${ }^{9}$ and it also gives an explanation for the sporadic performance of DFT based approaches in describing the PES of this deceptively simple looking molecule. ${ }^{10 \mathrm{~b}}$ In general, DFT in its standard formalism is not the preferred approach for studies of molecules in open-shell singlet states due to the limited applicability of unrestricted approaches in accurate description of near-degeneracy effects. ${ }^{27}$ For parent 1,2cyclopentadiene, this means that DFT can be reliably employed only for the $C_{2 v}$ symmetric ${ }^{1} A_{1}$ state whose wave function corresponds to the closed-shell carbenic configuration (Figure 2) and can be expressed as a single Slater determinant.

The electron localization function (ELF) provides a wave function independent, and perhaps a more easily accessible, approach for the analysis of electronic structures 
of molecules. Quantum mechanically, ELF is the angularly averaged measure of the curvature of the Fermi hole which in turn can be understood as the kinetic energy density of the relative motion pairs of same spin electrons centered at an arbitrary point in space. ${ }^{19}$ Since ELF is a scalar function, a topological analysis of its gradient field can be used to partition the molecular space into core and valence basins. For main group compounds, the number, population and synaptic order (the number of connections from a valence basin to core basins) of ELF basins generally correlate well with the qualitative domains of the VSEPR model. From this outset, we determined the ELFs for the different electronic states of 4 using the CAS(4,4)/def2-TZVPP optimized wave functions (see Figure 3).

It is evident from Figure 3 that the calculated ELFs correlate very well with the composition of the respective wave functions. For example, the ELF determined for the ground state of $\mathbf{4}$ is very much carbene-like although the population of the $\sigma$-lone pair basin at the middle carbon atom is less than a full electron pair (1.36 $\left.\mathrm{e}^{-}\right)$. However, this can be readily understood if one takes into account the coefficient of the $\mathrm{HOMO} \rightarrow$ LUMO excited determinant in the $\mathrm{Cl}$ expansion. That is, singlet diradical character leads to transfer of electrons from the $\sigma$-lone pair to the $\pi$-framework. The same reasoning also applies to the planar ${ }^{1} A_{1}$ and ${ }^{1} A_{2}$ states which show either an increase or a decrease in the $\sigma$-lone pair basin population, respectively, depending on the importance of the carbenic reference determinant in the total CAS wave function. It is particularly noteworthy that the ELF for the ${ }^{1} \mathrm{~A}_{1}$ state of 4 shows a fully developed $\sigma$ lone pair basin, which is in agreement with an electronic structure of a closed-shell singlet carbene. 


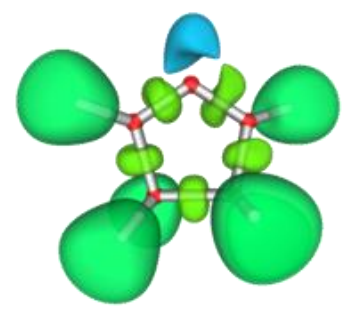

${ }^{1} \mathrm{~A}$

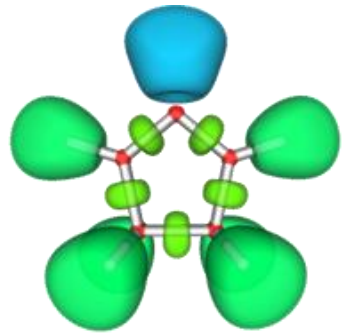

${ }^{1} \mathrm{~A}_{1}$

$$
\begin{aligned}
V(C) & =2.26 \\
V(C=C) & =2.56
\end{aligned}
$$

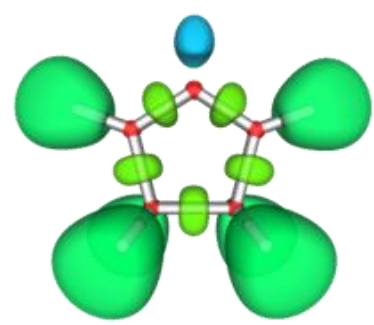

${ }^{1} \mathrm{~A}_{2}$

$\mathrm{V}(\mathrm{C})=1.22$

$\mathrm{V}(\mathrm{C}=\mathrm{C})=2.94$

Figure 3. Visualizations of the electron localization function (with selected basin populations) calculated for different electronic states of 4 at the CAS $(4,4) /$ def2-TZVPP level.

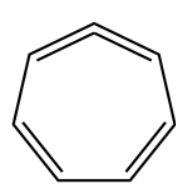

6

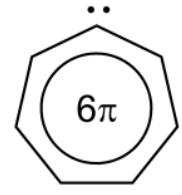

6

The PES calculated for 1,2-cyclopentadiene is reminiscent of that reported for 1,2,4,6-cycloheptatetraene, $6 .^{28}$ Although the energy landscapes of the two molecules are qualitatively very similar (Figure 2), there are some quantitative differences as well. In particular, the energy gap between the ground state and the excited diradical $\left({ }^{1} \mathrm{~A}_{2}\right)$ and carbenic $\left({ }^{1} A_{1}\right)$ states is considerably higher in 1,2,4,6-cycloheptatetraene than in 1,2-cyclopentadiene. This is readily attributed to the smaller ring size in $\mathbf{4}$ which gives its ground state a carbene-like electronic structure with a small diradical component. In contrast, the ground state of $\mathbf{6}$ differs significantly from its excited states as it is closedshell and purely allenic: at a $-\mathrm{C}=\mathrm{C}=\mathrm{C}-$ bond angle of roughly $145^{\circ}$, the $\pi$-type frontier orbitals in $\mathbf{6}$ remain essentially degenerate and there is no indication of a multireference character in the wave function. ${ }^{28}$ Thus, it appears clear why 1,2,4,6-cycloheptatetraene, albeit extremely reactive, can be studied spectroscopically in a low temperature 
matrix $^{29}$ or inside a host molecule, ${ }^{30}$ whereas only indirect evidence of the fleeting existence of 1,2-cyclopentadiene is found in the literature. ${ }^{9}$

While the ground state of 6 is allenic, and clearly acts as such, the electronic structure of its ${ }^{1} \mathrm{~A}_{1}$ excited state corresponds to that of a highly reactive singlet carbene, 2,4,6-cycloheptatrienylidene, $\mathbf{6}^{\prime}$. Even though $\mathbf{6}^{\prime}$ is not a stable molecule per se, it can be trapped as an adduct or, more importantly, coordinated in $\eta^{1}$ fashion to a range of different transition metals. ${ }^{31}$ In light of the energy difference between $\mathbf{6}$ and 6' (Figure 2), the latter finding might at first seem surprising, but the formation of the metal-carbon bond provides sufficient stabilization for coordination complexes of 2,4,6cycloheptatrienylidene to exist as isolable and characterizable entities with strong $\sigma$ donor character. ${ }^{32}$ In an analogous fashion, it seems reasonable to assume that also 1,2cyclopentadiene would form stable coordination complexes in which the ligand binds to the metal via its carbenic ${ }^{1} \mathrm{~A}_{1}$ excited state, provided that a feasible synthetic pathway for the ligand can be devised (vide infra). This conclusion is further supported by the fact that even the ground state of $\mathbf{4}$ is carbene-like ( $\sigma$-lone pair) and that the energy difference to the ${ }^{1} A_{1}$ state is only half of that found for 1,2,4,6-cycloheptatetraene. Consequently, even though $\eta^{2}$-type complexes of 6 exist with poorly acidic metal fragments, such as $\mathrm{Pt}(0)$ in $\mathrm{d}^{10}$ electronic configuration, ${ }^{33}$ the ligand $\mathbf{4}$ is expected to bind to metals solely in $\eta^{1}$ fashion.

Coordination complexes of 1, 3, 4 and 5: The ligand properties of pyrazolium-based systems 1 and $\mathbf{3}$ were characterized by performing geometry optimizations and detailed bonding analyses for coordination complexes of $\mathrm{MeO}_{\mathbf{1}}$ and $\mathrm{Me}_{\mathbf{3}}$ with different metal fragments (Chart 1 ). The potential applicability of $\mathbf{4}$ and its derivatives as $\sigma$-donors was assessed in a similar fashion by employing 1,3-dimethyl- (Me 4) and 1,3-dimethoxy-1,2cyclopentadiene $\left(\mathrm{MeO}_{4}\right)$ as ligands. The $\mathrm{N}$-methylated derivative of imidazol-2-ylidene, Me5, was used as a reference point throughout the calculations. 


$$
\begin{array}{llll}
\mathrm{L}-\mathrm{Mo}(\mathrm{CO})_{5} & \mathrm{~L}-\mathrm{Rh}(\mathrm{CO})_{2} \mathrm{Cl} & \mathrm{L}-\mathrm{PdCl}_{2}(\mathrm{py}) & \mathrm{L}-\mathrm{AgCl} \\
\mathrm{L}-\mathrm{W}(\mathrm{CO})_{5} & \mathrm{~L}-\mathrm{Ir}(\mathrm{CO})_{2} \mathrm{Cl} & \mathrm{L}-\mathrm{PtCl}_{2}(\mathrm{py}) & \mathrm{L}-\mathrm{AuCl}
\end{array}
$$

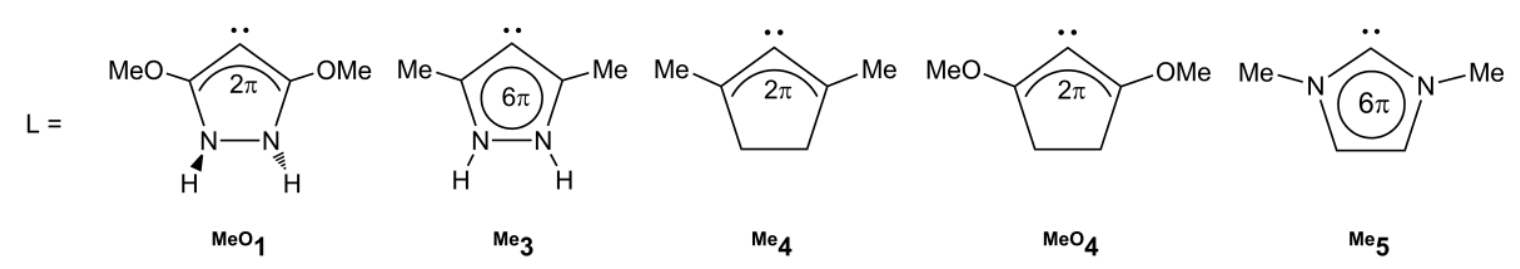

Chart 1.

Before entering the discussion of the properties of the studied metal complexes, it is instructive to summarize some key factors concerning the free ligands. As shown in Figure 4, the frontier Kohn-Sham orbitals of the ligands have notably similar morphologies with major differences primarily in their relative energies. The HOMO-LUMO gap is by far the smallest for the ${ }^{1} \mathrm{~A}_{1}$ state of ${ }^{\mathrm{Me}} \mathbf{4}(2.55 \mathrm{eV})$ and the largest for $\mathrm{Me}^{5}(6.81 \mathrm{eV})$. The values for $\mathrm{MeO}_{4}(4.24 \mathrm{eV}), \mathrm{Me}_{3}(4.43 \mathrm{eV})$ and ${ }^{\mathrm{MeO}_{1}}(5.27 \mathrm{eV})$ fall in between these two extremes, with the trend in calculated gaps following the experimentally known stability of the molecules. ${ }^{1,7,9}$ For all systems studied, the HOMO is a $\sigma$-type lone pair orbital at the central carbon atom of the CCC (NCN in Me5) fragment. Its energy is found to decrease in the order $\mathrm{Me}_{4} \approx \mathrm{Me}_{3}>\mathrm{OMe}_{4} \approx \mathrm{OMe}_{1}>\mathrm{Me}_{5}$ which gives a crude estimate of the electron-donating ability of the different ligands. However, as shown below, there exists no simple correlation between the HOMO energy and the data from the energy decomposition analysis (EDA) of the metal-carbon bond in the studied complexes.

In Me 4, the orbital energy gap is the most affected by the energy of the LUMO which resides markedly lower than in any other ligand examined. This orbital forms a bonding/anti-bonding pair with HOMO-1 and in Me 4 they both contain a particularly high contribution from the $\mathrm{p}_{\pi}$ atomic orbitals (AOs) of the terminal carbon atoms of the CCC fragment. This is because in ${ }^{\mathrm{Me}} \mathbf{4}$ there is no other possibility for $\pi$-delocalization to take place. Consequently, the carbon $\mathrm{p}_{\pi} \mathrm{AOs}$ appear at the HOMO and HOMO-1 with high coefficients, which also functions to decrease their energies. Extension of the $\pi$ - 
framework via endocyclic ( $\mathrm{Me}_{3}$ and $\mathrm{Me}_{5}$ ) or exocyclic $\left(\mathrm{MeO}_{4}\right)$ substitution, or by both simultaneously ( $\mathrm{MeO}^{1}$ ), naturally leads to changes in the shapes and energies of the respective MOs (Figure 4). It is therefore not entirely surprising that the ground state of $\mathrm{MeO}_{4}$ is the closed-shell carbenic ${ }^{1} \mathrm{~A}_{1}$ state with a HOMO-LUMO gap of almost double the size for $\mathrm{Me}^{4}$. Hence, as far as the stability of the free ligands is concerned, derivatives of 1,2-cyclopentadiene with exocyclic $\pi$-substituents seem the most attractive synthetic targets. However, the increased stability of $\mathrm{MeO}_{\mathbf{4}}$ over $\mathrm{Me}_{\mathbf{4}}$ is counterbalanced by significant weakening of the metal-carbon bond in their coordination complexes (vide infra).
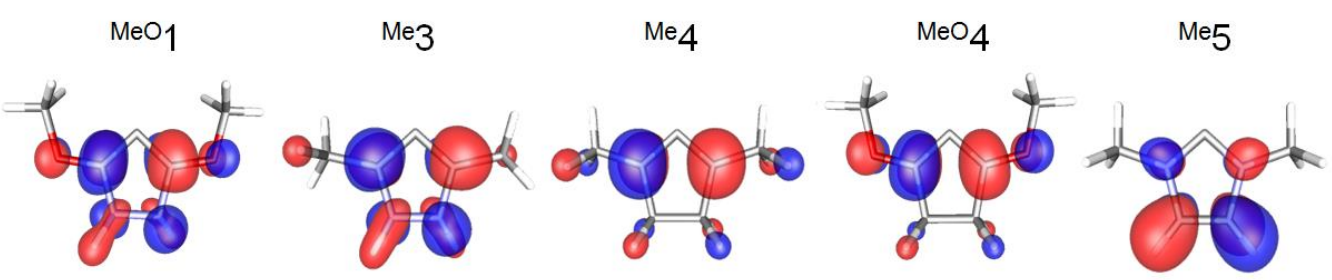

LUMO
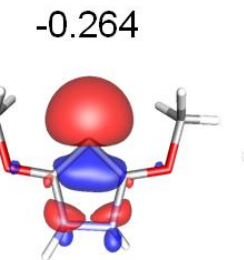

$-0.381$

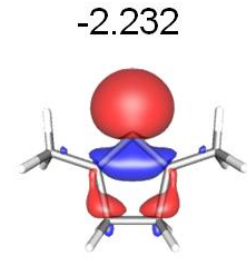

$-1.135$

0.765
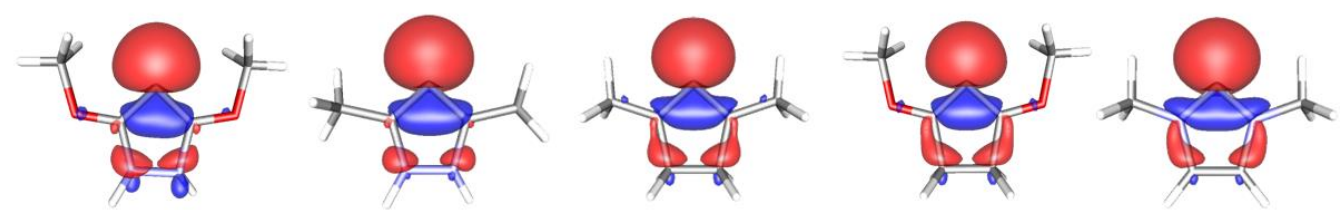

HOMO
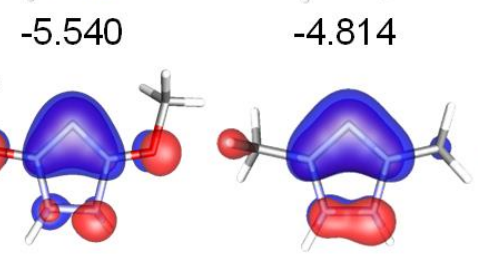

$-4.885$

$-5.377$

$-6.046$
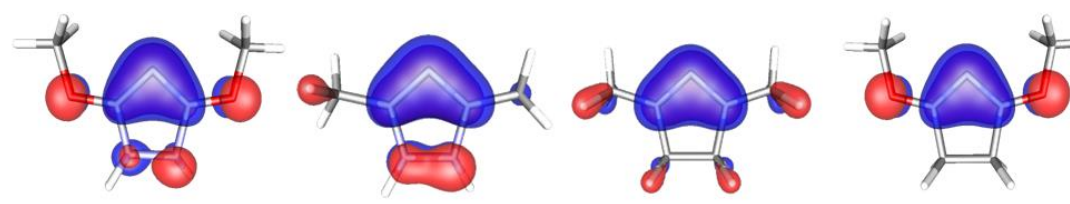

HOMO-1 $\quad-6.465$

$-6.483$

$-7.479$

$-6.754$

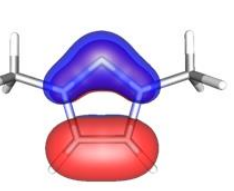

$-6.550$

Figure 4. Selected frontier Kohn-Sham orbitals of the studied ligands calculated at the PBE1PBE/def2-TZVPP level of theory. Orbital energies are given in eV.

Though not a topic of this paper, we note that the morphology of the $\pi$-type HOMO-1 of Me 4 gives no indication of zero-valent nature for the middle carbon atom $c f$. bonding in carbodicarbenes. ${ }^{6}$ In contrast, due to the presence of exocyclic $\pi$-donating substituents, the HOMO-1 of $\mathrm{MeO}_{4}$ has the largest contribution from the carbenic carbon center. For $\mathbf{1}$ this leads to unusually high second proton affinity, but the ligand is unable 
to bind to two main group Lewis acids mostly due to steric repulsion associated with the pendant -OR arms. ${ }^{5}$ Calculations conducted for $\mathrm{MeO}_{4}$ show that exocyclic substituents alone are not sufficient to polarize the $\pi$-framework: the second proton affinity of $\mathrm{MeO}_{4}$ is almost half of that found for $\mathrm{MeO}_{1}$. Consequently, neither $\mathrm{Me}_{\mathbf{4}}$ nor $\mathrm{MeO}_{\mathbf{4}}$ is expected to show carbon(0)-type reactivity.

The optimized geometries of the studied metal complexes are shown in Figure 5. We stress that even though the ground state of $\mathrm{Me}^{4}$ cannot be accurately modeled with DFT, the approach provides an excellent description of its metal complexes due to the fact that the ligand uses the excited ${ }^{1} A_{1}$ state for coordination (vide supra). Consequently, all tests of internal instabilities in the Kohn-Sham solutions of complexes involving Me 4 came back negative, thereby confirming the closed-shell nature of the ligand in the studied systems.

As a general note, the theoretically predicted structures for the investigated metal complexes are in excellent agreement with crystallographic data of systems involving 1, 3 and 5:1,7d,34 the PBE1PBE/def2-TZVPP method reproduces the experimental bond lengths and angles to an accuracy of few picometers and degrees, respectively. As evident from Figure 5, the propensity of the ligand ${ }^{\mathrm{Me}} \mathbf{4}$ to coordinate to metals via the ${ }^{1} A_{1}$ state is clearly reflected in the calculated metric parameters: in each case, the five-membered ring is fully planar, the key $C-C$ bonds are roughly $1.40 \AA$ and the CCC bond angle spans a narrow range from 103 to $106^{\circ}$ (see Figure 2). Overall, the coordinated geometry of the ligand is very similar to that found for Me3 and Me5, even though the latter contains an NCN fragment, whereas both ${ }^{\mathrm{MeO}_{1}}$ and ${ }^{\mathrm{MeO}_{4}}$ display more acute CCC bond angles in their metal complexes. The optimized metal-carbon bonds show a somewhat more pronounced trend: coordination complexes involving ligands $\mathrm{MeO}_{1}$ and $\mathrm{MeO}_{4}$ consistently display longer metal-carbon interactions as compared to the other systems examined in this work. This can be attributed in part to steric hindrance between the metal fragment and the bulky pendant $\mathrm{MeO}-$ arms of the ligands, which is also apparent from the geometries of the studied square planar complexes shown in 
Figure 5. All together, the variation in the key metrical parameters is, however, very small, indicative of no fundamental differences in the type of bonding (dative).

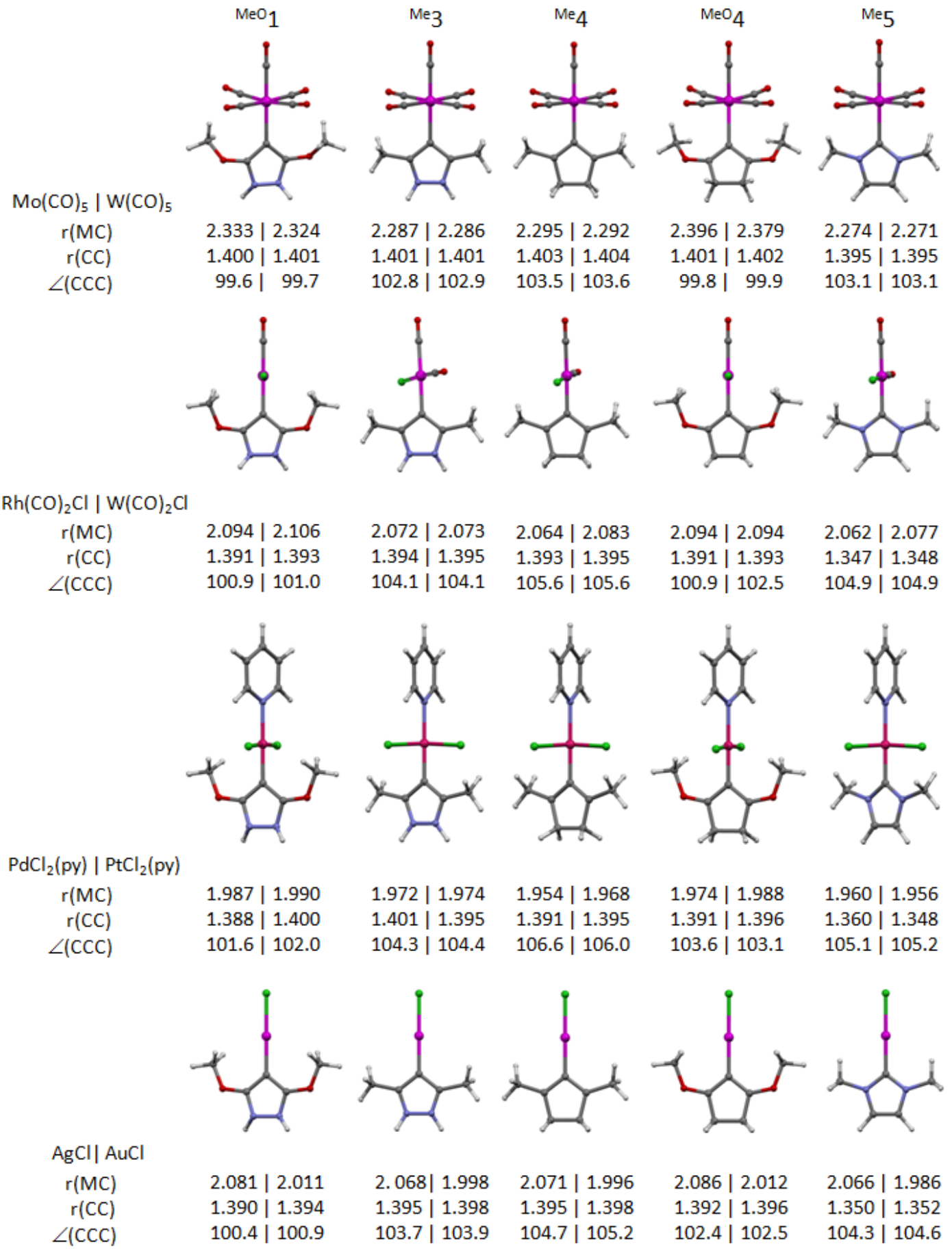

Figure 5. Optimized (PBE1PBE/def2-TZVPP) structures of the studied metal complexes. Selected bond lengths are reported in Ångströms $(\AA)$ and bond angles in degrees $\left({ }^{\circ}\right)$. 
In all metal complexes studied, the ligand ${ }^{\mathrm{Me}} \mathbf{4}$ adopts an $\eta^{1}$ coordination mode as expected based on its electronic structure (one $\sigma$-type lone pair). This is in contrast to the behavior observed experimentally for 1,2-cyclohexadiene for which the sole crystallographically characterized coordination compound contains an $\eta^{2}$ bound allenic ligand. ${ }^{35}$ The variation in the binding capabilities of 1,2-cyclopenta- and -hexadiene, molecules which differ by only one methylene fragment, can readily be explained by their different electronic structures: 1,2-cyclohexadiene has an allene-type ground state with no noticeable localization of a sigma lone pair at the middle carbon atom. ${ }^{3 a}$ Furthermore, the energy difference between its ground state and the carbenic ${ }^{1} A_{1}$ excited state is $240 \mathrm{~kJ} \mathrm{~mol}^{-1}$, which ensures that metal complexes incorporating 1,2cyclohexadiene will display an $\eta^{2}$ bound ligand unless extremely acidic metal fragments are employed.

In order to gain deeper insight into the metal-ligand bonding in the studied complexes, energy decomposition analyses ${ }^{21}$ were carried out for the optimized structures at the PBEPBE/TZP level. The EDA procedure combines the fragment approach to molecular structure with the decomposition of the instantaneous interaction energy $\left(\Delta E_{\text {int }}\right)$ to a sum of three terms -the Pauli repulsion $\left(\Delta E_{\text {Pauli }}\right)$, electrostatic interaction $\left(\Delta E_{\text {elstat }}\right)$ and orbital interaction $\left(\Delta E_{\text {orb }}\right)-$ involving individual, pre-chosen, fragments of the system i.e. $\Delta E_{\text {int }}=\Delta E_{\text {Pauli }}+\Delta E_{\text {elstat }}+\Delta E_{\text {orb. }}$. The Pauli repulsion contributes to the destabilizing (steric) interactions between the fragments, whereas the contributions from the orbital and electrostatic interaction terms are both stabilizing. The orbital interaction term can further be divided according to the contributions from the irreducible representations of the molecular point group, which allows e.g. the determination of $\sigma$ - and $\pi$-contributions to the total orbital interaction. Hence, the EDA describes in physically meaningful terms the bonding interaction between the selected fragments within the geometries that they adopt in the complex. It should be noted here that the calculated interaction energy is not the negative of bond dissociation energy (BDE) as the latter takes into account the energy gained from the relaxation of the structures of the individual fragments to their optimum 
geometries, $E_{\mathrm{r} \mid x}$, i.e. $\mathrm{BDE}=-\left(\Delta E_{\mathrm{int}}+E_{\mathrm{rl} x}\right)$. However, when comparing bonding in multiple similar systems, the trends in calculated interaction energies generally parallel the trends in bond dissociation energies.

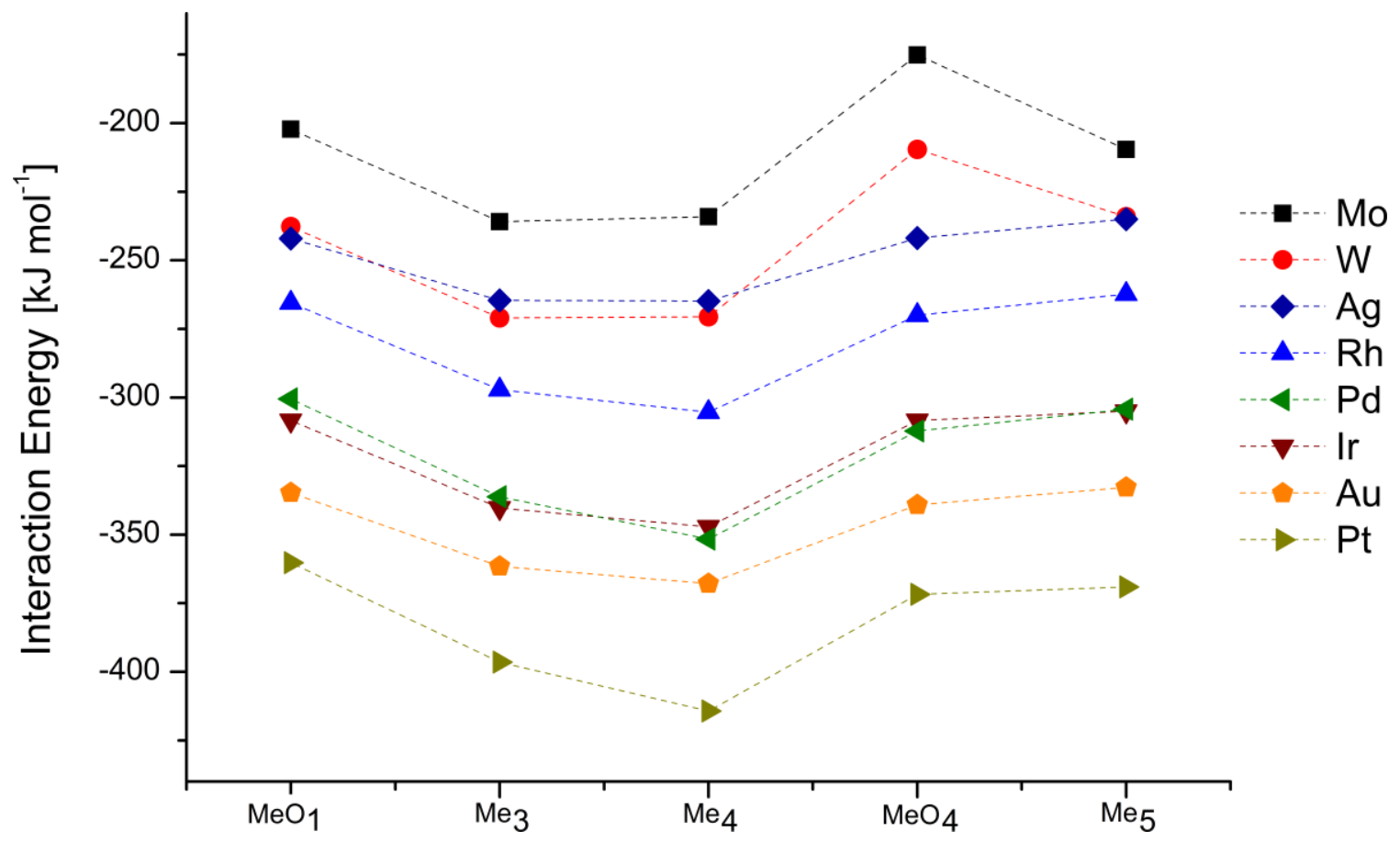

Figure 6. Graphical representation of trends in EDA interaction energies ( $\left.\Delta E_{\text {int }}\right)$ calculated for the metal complexes studied in this work.

The calculated EDA interaction energies of the studied metal complexes are shown schematically in Figure 6; a breakup of the numbers into individual energy terms is given in detail in Table 1. The graph in Figure 6 reveals two clear trends. First, irrespective of the identity of the ligand, the calculated interaction energies range from -200 to -400 $\mathrm{kJ} \mathrm{mol}{ }^{-1}$ and the strength of the interaction increases in the order Mo $>\mathrm{Ag} \approx \mathrm{W}>\mathrm{Rh}>$ $\mathrm{Pd} \approx \mathrm{Ir}>\mathrm{Au}>\mathrm{Pt}$. Second, for each metal complex studied, the ligands $\mathrm{Me}_{3}$ and $\mathrm{Me}_{4}$ always form the strongest bonds, whereas the relative ordering of the other ligands depends on the metal fragment in question though the differences are generally small. Consequently, the binding ability of the studied ligands is not readily inferable from their HOMO energies alone (vide supra) nor from the calculated metal-carbon bond lengths. Furthermore, the calculated $\Delta E_{\text {int }}$ values are similar for complexes of $\mathrm{Me}_{3}$ and 
Me $\mathbf{4}$, as is also true for ${ }^{\mathrm{OMe}} \mathbf{1}, \mathrm{OMe}_{\mathbf{4}}$ and ${ }^{\mathrm{Me}} \mathbf{5}$. The only exception to the latter generalization is afforded by the pentacarbonyl complexes of ${ }^{\mathrm{OMe}} \mathbf{4}$ which display unusually weak bonds due to steric reasons; the repulsion between the $\mathrm{CO}$ ligands and the pendant $\mathrm{MeO}-$ arms is also seen in the optimized geometries which show very long metal-carbon bonds and a slightly tilted bonding geometry for the ligand.

The energy terms listed in Table 1 show that, throughout the investigated systems, the metal-ligand attractive interactions are roughly two thirds electrostatic and one third covalent. The $\Delta E_{\text {orb }}$ term is always the smallest for $\mathrm{Me}_{\mathbf{3}}$ and $\mathrm{Me}_{\mathbf{4}}$. This is fully in line with the energetically high-lying HOMO of the ligands i.e. both systems benefit significantly from relaxation of the orbitals upon coordination to a metal. However, changes in orbital interactions do not alone explain changes in the calculated total interaction energies as differences in $\Delta E_{\text {int }}$ are always greater than in $\Delta E_{\text {orb }}$ alone. Consequently, the relative magnitude of $\Delta E_{\text {Pauli }}$ and $\Delta E_{\text {elstat }}$ terms plays an equally important role as $\Delta E_{\text {orb }}$ in determining the total interaction energy.

While both $\Delta E_{\text {Pauli }}$ and $\Delta E_{\text {elstat }}$ are, in the absolute sense, greatest for complexes involving ${ }^{\mathrm{4}} \mathbf{4}$, their sum is by far one of the smallest and therefore most favorable for bonding. For a given metal fragment, the trend in $\Delta E_{\text {Pauli }}$ parallels that in $\Delta E_{\text {orb }}$ as they are both determined by orbital overlap. ${ }^{36}$ In contrast, $\Delta E_{\text {elstat }}$ comes mainly from the interactions of the ligand lone-pair orbital with the metal nucleus and it is found to increase in the order $\mathrm{Me}_{4}<\mathrm{Me}_{3}<\mathrm{MeO}_{4}<\mathrm{Me}_{5}<\mathrm{MeO}_{1}$. It is known from theory that $\Delta E_{\text {elstat }}$ becomes particularly attractive when the electrons in question occupy a $p_{\sigma}$-type $A O .^{36}$ In other words, the more s-character the $\sigma$-type lone-pair orbital has, the smaller the observed electron-nucleus attraction will be. ${ }^{37}$ An inspection of the coefficients for the Kohn-Sham orbitals in Figure 4 shows that the contribution from the carbon $p_{\sigma}$-type AOs to the $\mathrm{HOMO}$ is the smallest for $\mathrm{MeO}_{\mathbf{1}}$ and $\mathrm{Me}_{\mathbf{5}}$ and the highest for $\mathrm{Me}_{\mathbf{3}}$ and $\mathrm{Me}_{\mathbf{4}}$, in good

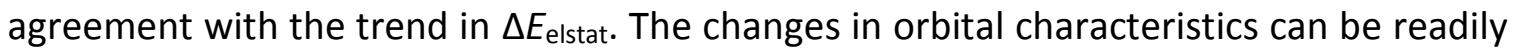
explained by the presence (or absence) of electronegative heteroatoms which polarize the $\sigma$-bonding framework, yielding a low-energy s-type lone pair HOMO (Figure 4). ${ }^{38}$ 
Table 1. Results (in $\mathrm{kJ} \mathrm{mol}^{-1}$ ) from energy decomposition analysis of metal-carbon bonding in coordination complexes examined in the current work.

\begin{tabular}{|c|c|c|c|c|c|c|}
\hline$M$ & & $\mathrm{MeO}_{1}$ & $\mathrm{Me}_{3}$ & $\mathrm{Me}_{4}$ & $\mathrm{MeO}_{4}$ & $\mathrm{Me}_{5}$ \\
\hline \multirow[t]{5}{*}{ Mo } & $\Delta E_{\text {Pauli }}$ & 396 & 447 & 458 & 346 & 427 \\
\hline & $\Delta E_{\text {elstat }}$ & -413 & -480 & -487 & -352 & -444 \\
\hline & $\Delta E_{\text {orb }}$ & -184 & -203 & -205 & -169 & -192 \\
\hline & $\Delta E_{\mathrm{int}}$ & -202 & -236 & -234 & -175 & -210 \\
\hline & BDE & 154 & 240 & 233 & 147 & 202 \\
\hline \multirow[t]{5}{*}{$\mathbf{W}$} & $\Delta E_{\text {Pauli }}$ & 460 & 514 & 530 & 412 & 458 \\
\hline & $\Delta E_{\text {elstat }}$ & -489 & -562 & -574 & -426 & -487 \\
\hline & $\Delta E_{\text {orb }}$ & -208 & -224 & -227 & -196 & -205 \\
\hline & $\Delta E_{\mathrm{int}}$ & -238 & -271 & -271 & -201 & -234 \\
\hline & BDE & 179 & 267 & 260 & 171 & 227 \\
\hline \multirow[t]{5}{*}{$\mathbf{R h}$} & $\Delta E_{\text {Pauli }}$ & 709 & 730 & 780 & 757 & 717 \\
\hline & $\Delta E_{\text {elstat }}$ & -690 & -731 & -778 & -728 & -698 \\
\hline & $\Delta E_{\text {orb }}$ & -284 & -296 & -308 & -298 & -281 \\
\hline & $\Delta E_{\mathrm{int}}$ & -266 & -297 & -305 & -270 & -262 \\
\hline & $\mathrm{BDE}$ & 241 & 283 & 286 & 241 & 243 \\
\hline \multirow[t]{5}{*}{ Ir } & $\Delta E_{\text {Pauli }}$ & 856 & 876 & 924 & 947 & 861 \\
\hline & $\Delta E_{\text {elstat }}$ & -827 & -869 & -917 & -897 & -834 \\
\hline & $\Delta E_{\text {orb }}$ & -337 & -346 & -354 & -358 & -332 \\
\hline & $\Delta E_{\mathrm{int}}$ & -308 & -340 & -347 & -308 & -305 \\
\hline & $\mathrm{BDE}$ & 256 & 305 & 306 & 258 & 262 \\
\hline \multirow[t]{5}{*}{$\mathbf{P d}$} & $\Delta E_{\text {Pauli }}$ & 921 & 954 & 1019 & 987 & 949 \\
\hline & $\Delta E_{\text {elstat }}$ & -858 & -909 & -973 & -915 & -886 \\
\hline & $\Delta E_{\text {orb }}$ & -364 & -381 & -398 & -385 & -367 \\
\hline & $\Delta E_{\mathrm{int}}$ & -301 & -336 & -352 & -312 & -304 \\
\hline & $\mathrm{BDE}$ & 285 & 328 & 338 & 290 & 290 \\
\hline \multirow[t]{5}{*}{$\mathrm{Pt}$} & $\Delta E_{\text {Pauli }}$ & 1095 & 1131 & 1205 & 1164 & 1138 \\
\hline & $\Delta E_{\text {elstat }}$ & -1029 & -1085 & -1161 & -1090 & -1073 \\
\hline & $\Delta E_{\text {orb }}$ & -427 & -442 & -458 & -445 & -434 \\
\hline & $\Delta E_{\mathrm{int}}$ & -360 & -396 & -414 & -372 & -369 \\
\hline & $\mathrm{BDE}$ & 326 & 374 & 383 & 329 & 339 \\
\hline \multirow[t]{5}{*}{$\mathrm{Ag}$} & $\Delta E_{\text {Pauli }}$ & 550 & 564 & 578 & 578 & 550 \\
\hline & $\Delta E_{\text {elstat }}$ & -620 & -655 & -664 & -643 & -613 \\
\hline & $\Delta E_{\text {orb }}$ & -172 & -173 & -178 & -177 & -172 \\
\hline & $\Delta E_{\mathrm{int}}$ & -242 & -265 & -264 & -242 & -235 \\
\hline & $\mathrm{BDE}$ & 234 & 264 & 261 & 231 & 228 \\
\hline \multirow[t]{5}{*}{$\mathrm{Au}$} & $\Delta E_{\text {Pauli }}$ & 870 & 895 & 930 & 917 & 901 \\
\hline & $\Delta E_{\text {elstat }}$ & -917 & -963 & -994 & -958 & -938 \\
\hline & $\Delta E_{\text {orb }}$ & -288 & -294 & -303 & -298 & -295 \\
\hline & $\Delta E_{\mathrm{int}}$ & -335 & -362 & -367 & -339 & -333 \\
\hline & $\mathrm{BDE}$ & 327 & 364 & 366 & 327 & 331 \\
\hline
\end{tabular}


To ensure that the trends in $\Delta E_{\text {int }}$ parallel the trends in binding energies, we calculated the latter set of values from the PBE1PBE/def2-TZVPP data (Table 1). As expected, the inclusion of relaxation energy merely scales the instantaneous interaction energies by a value whose magnitude is small compared to $\Delta E_{\text {int }}$ and virtually independent of the identity of the ligand in question. The only exception to the above are, again, the pentacarbonyl complexes of $\mathrm{MeO}_{1}$ and $\mathrm{MeO}_{4}$ for which the geometry of the coordinated ligand differs significantly from the free species (vide supra).

As discussed above, $\Delta E_{\text {orb }}$ is a sum of individual interactions spanning all irreducible representations within the molecular point group. Hence, provided that suitable symmetry elements exist, this term can be divided into $\sigma$ - and $\pi$-type contributions. Although the majority of complexes examined in the current study adopt an appropriate point group for symmetry-based partitioning of $\Delta E_{\text {orb }}$ (either $C_{2}$ or $C_{2 v}$ ), complexes involving group 9 metals posses no symmetry elements and are excluded from the analysis. A division of $\Delta E_{\text {orb }}$ for the remaining set of structures shows that in all complexes, the metal-carbon bonds are, as anticipated, predominantly of $\sigma$-type $(\approx$ 80-85\%) involving dative bonding between the HOMO of the ligand and the LUMO of the metal fragment. Since there are no major ligand dependent differences in the data, all studied systems can be classified as $\sigma$-donors with limited $\pi$-accepting capabilities. This parallels well with the morphology of their $\pi$-type LUMO that has a node at the carbenic carbon atom (Figure 2).

Although the current contribution is the first probing the electron donating properties of ligands of the type 1, 3 and 4, the EDA results can be compared to data presented by Frenking and co-workers for metal complexes of both normal and abnormal NHCs (aNHCs), that is, imidazol-2-ylidenes and imidazol-4-ylidenes of which the latter contain one nitrogen atom remote to the carbenic carbon center. ${ }^{39}$ The published results are in excellent agreement with our data, taking into account the different basis sets and functional used, as it was found that the investigated ligands bind to metals in almost pure $\sigma$-type fashion $(\approx 85 \%)$ and form metal-carbon bonds that are roughly two-thirds electrostatic and one third covalent. Furthermore, the $\Delta E_{\text {int }}$ 
values calculated for metal complexes of $a \mathrm{NHCs}$ fall almost exactly in between the data for $r$ NHCs (Me3) and normal NHCs (Me5). Consequently, each remote heteroatom leads to a decrease in the total interaction energy and, hence, an increase in the strength of the metal-ligand interaction. These results fully support the trends observed in the current work.

To summarize, the results from EDA show that all investigated ligands give rise to equally strong or even stronger $\sigma$-type metal-carbon interactions as the reference compound ${ }^{\mathrm{Me}} \mathbf{5}$. In the majority of cases, ligand $\mathrm{Me}_{\mathbf{4}}$ forms the strongest bonds and this behavior is attributed to its orbital structure. The absence of heteroatoms leaves the $\sigma$ framework unpolarized, yielding a lone pair HOMO with enhanced $p_{\sigma}$ character (affects $\Delta E_{\text {elstat }}$ ) and high orbital energy (affects $\Delta E_{\text {orb }}$ ). The data also illustrates that while introduction of exocyclic $\pi$-donor substituents to the molecular framework, yielding $\mathrm{MeO}_{1}$ and $\mathrm{MeO}_{4}$, leads to the generation of more stable ligands, it has a simultaneous adverse effect to the strength of the interactions of these systems with metal centers. In this respect, having two remote endocyclic heteroatoms offers a good compromise between stability and donor properties: the calculated $\Delta E_{\text {int }}$ values are very much comparable between $\mathrm{Me}^{3}$ and $\mathrm{Me}_{\mathbf{4}} \mathbf{4}$, and while neither of them is available as a free species, metal complexes of $\mathbf{3}$ are known to be thermodynamically stable and useable in various applications. ${ }^{8}$

Experimental considerations: All reported attempts to generate 1,2-cyclopentadiene by a reaction of the corresponding vinyl halides with bases ${ }^{40}$ or by photoexcitation of allyl anions incorporating efficient leaving groups ${ }^{41}$ have proven unsuccessful even though the same approaches can be used to synthesize cyclic allenes with ring sizes greater than or equal to six carbon atoms. The first method which successfully yielded a bicyclic derivative of 1,2-cyclopentadiene was reported by Balci et al. They utilized a DoeringMoore-Skattebol reaction of a bromofluorocyclopropane derivative in the presence of furan as the trapping agent (Scheme 1). ${ }^{\text {9a }}$ Shortly after the publication of this work, the same group reported the synthesis of 1-phenyl-cyclopenta-1,2-diene via base-induced 
HI-elimination reaction (Scheme 2). ${ }^{9 b}$ Despite the replacement of the double bond hydrogen with a phenyl group, the derivatized cyclopentene proved reluctant to undergo further reactions and its dehydroiodonation required drastic conditions: $240^{\circ} \mathrm{C}$ for $9 \mathrm{~h}$ in a sealed tube using benzene as the solvent/trapping agent. Interestingly, Balci and co-workers explained the formation of the observed products by assuming that the allene is in equilibrium with "its diradical isomer". ${ }^{9 b}$ However, as shown in the present study, even the ground state of $\mathbf{4}$ has diradical nature, which is in excellent agreement with its reactivity.

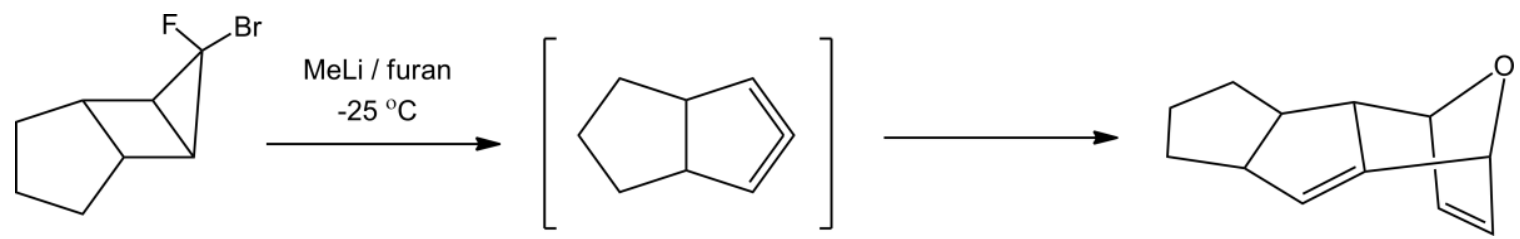

Scheme 1.

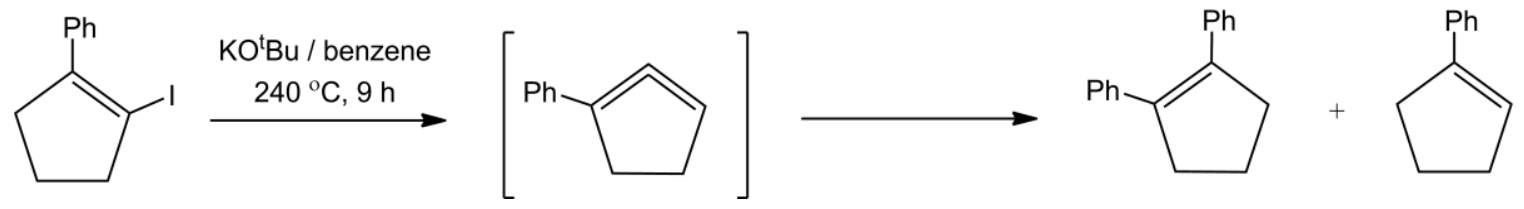

Scheme 2.

It is evident from above that the experimental realization of metal complexes of derivatives of 4 requires new approaches for the more facile formation of the ligand. In this respect, the recent report by Peña and Guitian for the straightforward synthesis of 1,2-cyclohexadiene under very mild reaction conditions is extremely interesting ${ }^{42}$ Their $^{2}$ method is based on a fluoride-induced $\beta$-elimination of (trimethylsilyl)cyclohexenyl triflates (Scheme 3). The exceptional leaving group character of the triflate group allows the synthesis of 1,2-cyclohexadiene at room temperature in an excellent yield: in THF solution, the reaction affords the dimerized product in $78 \%$ yield. An adaptation of this pathway for the synthesis of 1,2-cylopentadiene is certainly worth of consideration. 


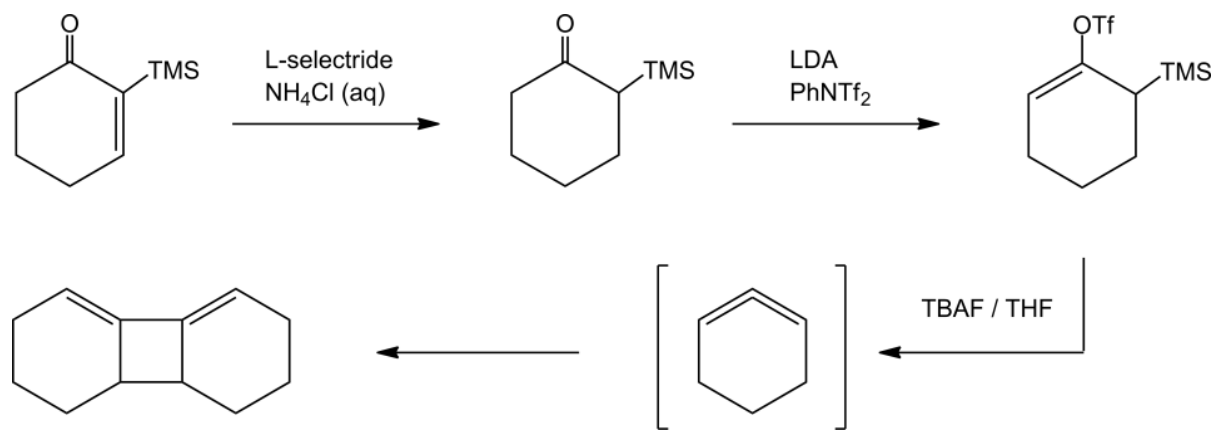

Scheme 3.

\section{Conclusions}

In this work, we have established using high-level quantum chemical calculations that the electronic ground state of 1,2-cyclopentadiene is the $C_{2}$-symmetric and carbene-like ${ }^{1} \mathrm{~A}$ state. Because of the relatively small HOMO-LUMO gap, the molecule has a diradical component in its wave function in addition to two low-lying singlet excited states with carbenic $\left({ }^{1} A_{1}\right)$ and diradical $\left({ }^{1} A_{2}\right)$ character. The calculated energy landscape is reminiscent of that determined for 1,2,4,6-cycloheptatetraene, a highly reactive cyclic allene that forms a variety of organometallic complexes in which the ligand binds to metals using the excited carbenic ${ }^{1} \mathrm{~A}_{1}$ state. In an analogous fashion, theoretical calculations for the transition metal complexes of 4 reveal that the five-membered ring acts as a particularly strong sigma donor that coordinates to metals solely in $\eta^{1}$ fashion.

Calculations probing the binding properties of ligands 1, 3 and 4 show that all systems display typical two-electron donor behavior and exhibit equal or stronger interactions with metal centers than NHCs based on the imidazol-2-ylidene framework. In particular, Me3 and ${ }^{\mathrm{Me}} \mathbf{4}$ are found to form the strongest bonds in the series, displaying metal-carbon bond dissociation energies that are consistently 30 to $50 \mathrm{~kJ} \mathrm{~mol}^{-1}$ higher than for other compounds investigated. The excellent binding properties of these ligands can be correlated to their orbital structure which allows efficient $\sigma$-type binding to metals, though at the expense of stability; opposite trends are obtained for the alkyloxy substituted variants $\mathrm{MeO}_{1}$ and $\mathrm{MeO}_{4}$. For $\mathrm{Me}_{\mathbf{4}}$, the calculated metal-carbon bond dissociation energies vary between 200 and $400 \mathrm{~kJ} \mathrm{~mol}^{-1}$, which lends strong support to 
the thermodynamic stability of the studied complexes and, hence, to the possibility of capturing derivatives of this ephemeral compound through in situ metallation of suitable precursors.

In recent years, there has been a tremendous shift in research emphasis from conventional NHCs based on the imidazol-2-ylidene framework towards carbenes with reduced or no heteroatom substitution as they often display superior binding characteristics. ${ }^{31,43}$ The current contribution adds to this discussion by investigating a series of compounds with a varying number of $\pi$-donor atoms and groups. The results clearly underscore the efficacy of purely carbocyclic frameworks in realizing new potent $\sigma$-donors. To increase stabilization, $\pi$-substituents with less electronegative character can be employed to leave the $\sigma$-framework unperturbed. In this respect, it is surprising that there appears to be no comprehensive theoretical investigations of metal-carbon bonding in coordination complexes of $\mathbf{6}^{\prime}$ and its different derivatives. Such calculations are currently underway in our group.

\section{Acknowledgment}

We are grateful to the Academy of Finland, the Technology Industries of Finland Centennial Foundation and the University of Jyväskylä for financial support of this research. We also thank CSC - the IT Center for Science for their support in providing computational resources.

Supporting Information available: Optimized structures of all investigated metal complexes as well as full details of results from energy decomposition analyses. This

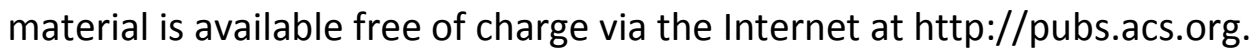




\section{References and Notes}

${ }^{1}$ a) V. Lavallo, C. A. Dyker, B. Donnadieu, G. Bertrand, Angew. Chem. Int. Ed. 2008, 47, 5411-5414; b) M. Melaimi, P. Parameswaran, B. Donnadieu, G. Frenking, G. Bertrand, Angew. Chem. Int. Ed. 2009, 48, 4792-4795.

2 a) P. W. Dillon, G. R. Underwood, J. Am. Chem. Soc. 1974, 96, 779-787; b) R. Johnson, Chem. Rev. 1989, 89, 1111-1124.

3 a) M. M. Hänninen, A. Peuronen, H. M. Tuononen, Chem. Eur. J. 2009, 15, 7287-7291;

b) I. Fernandez, C. A. Dyker, A. DeHope, B. Donnadieu, G. Frenking, G. Bertrand, J. Am. Chem. Soc. 2009, 131, 11875-11881; c) T. Hoeltzl, V. T. Ngan, M. T. Nguyen, T. Veszpremi, Chem. Phys. Lett. 2009, 481, 54-57.

${ }^{4}$ A. D. Ruiz, M. Melaimi, G. Bertrand, Abstracts of Papers, $239^{\text {th }}$ National Meeting of the American Chemical Society, San Francisco, CA, March 21-25, 2010; American Chemical Society: Washington, DC, 2010; INOR-495.

${ }^{5}$ S. Klein, R. Tonner, G. Frenking, Chem. Eur. J. 2010, 16, 10160-10170.

${ }^{6}$ a) R. Tonner, F. Öxler, B. Neumüller, W. Petz, G. Frenking, Angew. Chem. Int. Ed. 2006, 45, 8038-8042; b) R. Tonner, G. Frenking, Angew. Chem. Int. Ed. 2007, 46, 8695-8698; c) R. Tonner, G. Frenking, Chem. Eur. J. 2008, 14, 3260-3272; d) R. Tonner, G. Frenking, Chem. Eur. J. 2008, 14, 3273-3289; f) C. A. Dyker, V. Lavallo, B. Donnadieu, G. Bertrand, Angew. Chem. Int. Ed. 2008, 47, 4206-4209; g) M. Melaimi, M. Soleilhavoup, Guy Bertrand, Angew. Chem. Int. Ed. 2010, 49, 8810-8849.

7 a) Y. Han, H. V. Huynh, Chem. Commun. 2007, 1089-1091; b) Y. Han, H. V. Huynh, G. K. Tan, Organometallics 2007, 26, 6581-6585; c) Y. Han, L. J. Lee, H. V. Huynh, Organometallics 2009, 28, 2778-2786.

8 Y. Han, H. V. Huynh, Dalton Trans. 2011, 40, 2141-2147.

9 a) F. Algi, R. Özen, M. Balci, Tetrahedron Lett. 2002, 43, 3129-3131; b) M. Ceylan, S. Yalçin, H. Seçen, Y. Sütbeyaz, M. Balci, J. Chem. Res. (S) 2003, 21-23.

10 a) R. O. Jr. Angus, M. W. Schmidt, R. P. Johnson, J. Am. Chem. Soc. 1985, 107, 532-537; b) K. J. Daoust, S. M. Hernandez, K. M. Konrad, I. D. Mackie, J. Jr. Winstanley, R. P. Johnson, J. Org. Chem. 2006, 71, 5708-5714.

${ }^{11}$ Gaussian 09, Revision A.1, M. J. Frisch, G. W. Trucks, H. B. Schlegel, G. E. Scuseria, M. A. Robb, J. R. Cheeseman, G. Scalmani, V. Barone, B. Mennucci, G. A. Petersson, H. Nakatsuji, M. Caricato, X. Li, H. P. Hratchian, A. F. Izmaylov, J. Bloino, G. Zheng, J. L. Sonnenberg, M. Hada, M. Ehara, K. Toyota, R. Fukuda, J. Hasegawa, M. Ishida, T. Nakajima, Y. Honda, O. Kitao, H. Nakai, T. Vreven, J. A. Montgomery, Jr., J. E. Peralta, F. Ogliaro, M. Bearpark, J. J. Heyd, E. Brothers, K. N. Kudin, V. N. Staroverov, R. Kobayashi, J. Normand, K. Raghavachari, A. Rendell, J. C. Burant, S. S. Iyengar, J. Tomasi, M. Cossi, N. Rega, J. M. Millam, M. Klene, J. E. Knox, J. B. Cross, V. Bakken, C. Adamo, J. Jaramillo, R. Gomperts, R. E. Stratmann, O. Yazyev, A. J. Austin, R. Cammi, C. Pomelli, J. W. Ochterski, R. L. Martin, K. Morokuma, V. G. Zakrzewski, G. A. Voth, P. Salvador, J. J. Dannenberg, S. Dapprich, A. D. Daniels, Ö. Farkas, J. B. Foresman, J. V. Ortiz, J. Cioslowski, and D. J. Fox, Gaussian, Inc., Wallingford CT, 2009. 
12 MOLPRO, version 2009.1, a package of ab initio programs written by H.-J. Werner, P. J. Knowles, G. Knizia, F. R. Manby, M. Schütz, P. Celani, T. Korona, R. Lindh, A.

Mitrushenkov, G. Rauhut, K. R. Shamasundar, T. B. Adler, R. D. Amos, A. Bernhardsson, A. Berning, D. L. Cooper, M. J. O. Deegan, A. J. Dobbyn, F. Eckert, E. Goll, C. Hampel, A. Hesselmann, G. Hetzer, T. Hrenar, G. Jansen, C. Köppl, Y. Liu, A. W. Lloyd, R. A. Mata, A. J. May, S. J. McNicholas, W. Meyer, M. E. Mura, A. Nicklaß, D. P. O'Neill, P. Palmieri, K. Pflüger, R. Pitzer, M. Reiher, T. Shiozaki, H. Stoll, A. J. Stone, R. Tarroni, T. Thorsteinsson, M. Wang, A. Wolf.

${ }^{13}$ ADF2009, SCM, Theoretical Chemistry, Vrije Universiteit, Amsterdam, The Netherlands, http://www.scm.com, E. J. Baerends, T. Ziegler, J. Autschbach, D. Bashford, A. Bérces, F. M. Bickelhaupt, C. Bo, P. M. Boerrigter, L. Cavallo, D. P. Chong, L. Deng, R. M. Dickson, D. E. Ellis, M. van Faassen, L. Fan, T. H. Fischer, C. Fonseca Guerra, A. Ghysels, A. Giammona, S. J. A. van Gisbergen, A. W. Götz, J. A. Groeneveld, O. V. Gritsenko, M. Grüning, S. Gusarov, F. E. Harris, P. van den Hoek, C. R. Jacob, H. Jacobsen, L. Jensen, J. W. Kaminski, G. van Kessel, F. Kootstra, A. Kovalenko, M. V. Krykunov, E. van Lenthe, D. A. McCormack, A. Michalak, M. Mitoraj, J. Neugebauer, V. P. Nicu, L. Noodleman, V. P. Osinga, S. Patchkovskii, P. H. T. Philipsen, D. Post, C. C. Pye, W. Ravenek, J. I. Rodríguez, P. Ros, P. R. T. Schipper, G. Schreckenbach, J. S. Seldenthuis, M. Seth, J. G. Snijders, M. Solà, M. Swart, D. Swerhone, G. te Velde, P. Vernooijs, L. Versluis, L. Visscher, O. Visser, F. Wang, T. A. Wesolowski, E. M. van Wezenbeek, G. Wiesenekker, S. K. Wolff, T. K. Woo, A. L. Yakovlev.

14 a) J. P. Perdew, K. Burke, M. Ernzerhof, Phys. Rev. Lett. 1996, 77, 3865-3868; b) J. P. Perdew, K. Burke, M. Ernzerhof, Phys. Rev. Lett. 1997, 78, 1396; c) J. P. Perdew, M. Ernzerhof, K. Burke, J. Chem. Phys. 1996, 105, 9982-9985; d) C. Adamo, V. Barone, J. Chem. Phys. 1999, 110, 6158-6169.

15 B. E. Roos, P. R. Taylor, P. E. M. Siegbahn, Chem. Phys. 1980, 48, 157-173.

${ }^{16}$ K. Andersson, P.-Å. Malmqvist, B. O. Roos, J. Chem. Phys. 1992, 96, 1218-1226.

17 a) F. Weigend, M. Häser, H. Patzelt, R. Ahlrichs, Chem. Phys. Lett. 1998, 294, 143-152;

b) F. Weigend, R. Ahlrichs, Phys. Chem. Chem. Phys. 2005, 7, 3297-3305.

18 D. Andrae, U. Häussermann, M. Dolg, H. Stoll, H. Preuss, Theor. Chim. Acta 1990, 77, 123-141.

19 a) B. Silvi, A. Savin, Nature 1994, 371, 683-686; b) A. Savin, A. D. Becke, J. Flad, R. Nesper, H. Preuss, H. G. Schnering, Angew. Chem., Int. Ed. Engl. 1991, 30, 409-412; c) A. Savin, R. Nesper, S. Wengert, T. F. Fässler, Angew. Chem., Int. Ed. Engl. 1997, 36, $1808-2832$.

${ }^{20}$ S. Noury, X. Krokidis, F. Fuster, B. Silvi, TopMoD-09, Laboratoire de Chimie Théorique, Université P. \& M. Curie, Paris, France, 2009.

${ }^{21}$ F. M. Bickelhaupt, E. J. Baerends, in Rev. Comput. Chem., Eds. K. B. Lipkowitz, D. B. Boyd, Wiley-VCH: New York, 2000, Vol. 15, pp 1-86.

22 a) K. J. Morokuma, Chem. Phys. 1971, 55, 1236-1244; b) K. Kitaura, K. Morokuma, Int. J. Quantum. Chem. 1976, 10, 325-340; c) T. Ziegler, A. Rauk, Theoret. Chim. Acta 1977, 46, 1-10. 
${ }^{23}$ E. van Lenthe, E. J. Baerends, J. Comp. Chem. 2003, 24, 1142-1156.

24 a) E. van Lenthe, E. J. Baerends, J. G. Snijders, J. Chem. Phys. 1993, 99, 4597-4606; b) E. van Lenthe, E. J. Baerends, J. G. Snijders, J. Chem. Phys. 1994, 101, 9783-9790; c) E. van Lenthe, A. E. Ehlers, E. J. Baerends, J. Chem. Phys. 1999, 110, 8943-8953.

25 a) L. Laaksonen, J. Mol. Graph. 1992, 10, 33; b) D. L. Bergman, L. Laaksonen, A. Laaksonen, J. Mol. Graph. 1997, 15, 301.

${ }^{26}$ Mercury CSD 2.0 - New Features for the Visualization and Investigation of Crystal Structures C. F. Macrae, I. J. Bruno, J. A. Chisholm, P. R. Edgington, P. McCabe, E. Pidcock, L. Rodriguez-Monge, R. Taylor, J. van de Streek, P. A. Wood, J. Appl. Cryst. 2008, 41, 466-470.

27 J. Gräfenstein, E. Kraka, M. Filatov, D. Cremer, Int. J. Mol. Sci. 2002, 3, 360-394.

${ }^{28}$ P. R. Schreiner, W. L. Karney, P. v. R. Schleyer, W. T. Borden, T. P. Hamilton, H. F. III Schaefer, J. Org. Chem. 1996, 61, 7030-7039.

29 a) P. R. West, O. L. Chapman, J.-P. LeRoux, J. Am. Chem. Soc. 1982, 104, 1779-1782;

b) S. Matzinger, T. Bally, J. Phys. Chem. A 2000, 104, 3544-3552.

${ }^{30}$ R. Warmuth, M. A. Marvel, Angew. Chem. Int. Ed. 2000, 39, 1117-1119.

${ }^{31}$ K. Öfele, E. Tosh, C. Taubmann, W. A. Herrmann, Chem. Rev. 2009, 109, 3408-3444.

32 a) W. A. Herrmann, K. Öfele, S. K. Schneider, E. Herdtweck, S. D. Hoffmann, Angew.

Chem. Int. Ed. 2006, 45, 3859-3862; b) C. Taubmann, E. Tosh, K. Öfele, E. Herdtweck, W. A. Herrmann, J. Organomet. Chem. 2008, 693, 2231-2236.

33 a) W. R. Winchester, W. M. Jones, Organometallics 1985, 4, 2228-2230; b) W. R. Winchester, M. Gawron, G. J. Palenik, W. M. Jones, Organometallics 1985, 4, 1894-1896; c) F. J. Feher, D. Gergens, J. W. Ziller, Organometallics 1993, 12, 2810-2813. 34 a) D. M. Khramova, E. L. Rosena, J. A. V. Era, P. D. Vu, V. M. Lynch, C. W. Bielawski, Tetrahedron, 2008, 64, 6853-6862; b) H. M. Wang, C. S. Vasam, T. Y. R. Tsai, S.-H. Chen, A. H. H. Chang, I. J. B. Lin, Organometallics 2005, 24, 486-493; c) A. Zanardi, J. A. Mata, E. Peris, Organometallics 2009, 28, 4335-4339.

35 J. Yin, K. A. Abboud, W. M. Jones, J. Am. Chem. Soc. 1993, 115, 3810-3811.

${ }^{36}$ A. Krapp, F. M. Bickelhaupt, G. Frenking, Chem. Eur. J. 2006, 12, 9196-9216.

${ }^{37}$ G. Frenking, K. Wichmann, R. Fröhlich, J. Grobe, W. Golla, D. Le Van, B. Krebs, M. Läge, Organometallics 2002, 21, 2921-2930.

${ }^{38}$ S. K. Schneider, G. R. Julius, C. Loschen, H. G. Raubenheimer, G. Frenking, W. A. Herrmann, Dalton Trans. 2006, 1226-1233.

${ }^{39}$ R. Tonner, G. Heydenrych, G. Frenking, Chem. Asian J. 2007, 2, 1555-1567.

40 a) G. Wittig, J. Heyn, Justus Liebigs Ann. Chem. 1972, 756, 1-13; b) L. K. Montgomery, F. Scardiglia, J. D. Roberts, J. Am. Chem. Soc. 1965, 87, 1917-1925; c) L. K. Montgomery, L. E. Applegate, J. Am. Chem. Soc. 1967, 89, 2952-2960.

${ }^{41}$ L. M. Tolbert, M. N. Islam, R. P. Johnson, P. M. Loiselle, W. C. Shakespeare, J. Am. Chem. Soc. 1990, 112, 6416-6417.

42 I. Quintana, D. Peña, D. Pérez, E. Guitián, Eur. J. Org. Chem. 2009, 5519-5524.

43 O. Schuster, L. Yang, H. G. Raubenheimer, M. Albrecht, Chem. Rev. 2009, 109, 34453478. 